\title{
Variation in Pathogenicity and Genotype Among Single-Zoospore Strains of Aphanomyces euteiches
}

\author{
D. K. Malvick and J. A. Percich
}

Department of Plant Pathology, University of Minnesota-Twin Cities, St. Paul 55108.

Accepted for publication 2 October 1997.

\begin{abstract}
Malvick, D. K., and Percich, J. A. 1998. Variation in pathogenicity and genotype among single-zoospore strains of Aphanomyces euteiches. Phytopathology 88:52-57.

The role of asexual reproduction in the production of pathogenic and genotypic variation in Aphanomyces euteiches was investigated. Variation was studied among three groups of 18 single-zoospore progeny of $A$. euteiches derived from each of three single-zoospore parental strains. Pathogenicity was assessed by evaluating disease severity (DS) on roots of five pea lines possessing different levels of resistance to Aphanomyces root rot and of a susceptible cultivar of snap bean and alfalfa. None of the single-zoospore progeny incited significantly higher DS levels than
\end{abstract}

ABSTRACT their parental strain on any of the seven hosts; however, 3 or 4 of the 18 progeny in each group incited significantly lower DS than their parental strains. The host range of the progeny either decreased or remained the same as compared with parental strains. Genotypic variation was assessed with randomly amplified polymorphic DNA (RAPD) analysis. Polymorphic RAPD markers that distinguished parental and progeny strains were detected within two of the three groups of strains with two of four RAPD primers used. Of 76 total RAPD markers that were detected among all strains in all groups, four $(5 \%)$ were polymorphic. The polymorphic markers were not associated with the pathogenic variation.

Additional keywords: diversity, legumes, oomycete.
Aphanomyces euteiches Drechs. is a soilborne plant pathogen that infects a variety of legume species (16). Pea (Pisum sativum L.) is the crop that appears to be the most seriously damaged by Aphanomyces root rot, but alfalfa (Medicago sativa L.), snap bean (Phaseolus vulgaris L.), and red clover (Trifolium pratense L.) may also be damaged severely. A. euteiches, classified in the kingdom Chromista, division Oomycota, is a phenotypically and genotypically heterogeneous species. Different strains having selective host ranges on several legume species and cultivars have been characterized with pathogenicity and genotype studies $(7,9,12)$. The intraspecific variation within $A$. euteiches may at least partially explain why host resistance to this pathogen has been difficult to obtain. Additional information on the characteristics of diversity within this pathogen should enhance the development and deployment of disease-resistant legume cultivars and contribute to understanding the population biology of this organism.

Although intraspecific variability has been identified in $\mathrm{A}$. $\mathrm{eu}$ teiches, the source and mechanism by which the variability is generated is assumed, but has not been defined experimentally. Sexual recombination and somatic variability via asexual production of zoospores may be two sources of variation (15). Variation among single-zoospore strains has been reported for Oomycota. The most extensive studies of intraspecific variation have focused on Phytophthora sojae (a homothallic species) and $P$. infestans (a heterothallic species). Rutherford et al. (19) reported variation in virulence among single-zoospore isolates of $P$. sojae to the extent that some zoospore progeny had a different race classification than the parental strain. Pathogenic variation among single-zoospore cultures of $P$. infestans has also been reported $(2,3,11)$. The source and mechanisms of change were not reported; however, Caten (3) suggested "cytoplasmic changes" may lead to variation.

Corresponding author: D. K. Malvick

E-mail address: dmalvick@inwave.com

Publication no. P-1997-1112-03R

(C) 1998 The American Phytopathological Society
Somatic mutation or segregation, expressed as pathogenic variation among zoospores, has also been reported as a possible means by which diversity is generated in A. euteiches (9). Holub et al. (9) compared pathogenicity characteristics among single-zoospore progeny from one broad-host-range parental isolate. They reported somatic segregation for decreased virulence among the progeny using five legume species. Very little else has been reported on the generation of variation in A. euteiches. Furthermore, the role of sexual recombination in generating variation in A. euteiches is not understood. A. euteiches appears to reproduce homothallically, and the occurrence or importance of heterothallic reproduction is unknown. The lack of consistent and controlled germination of oospores in culture is a formidable barrier to investigating traits of potential progeny of crosses.

This investigation addressed the extent and basis of variation in A. euteiches that is expressed through asexually reproduced zoospores. Single-zoospore progeny from three different parental strains of $A$. euteiches were studied, and pathogenicity traits were investigated using pea, bean, and alfalfa cultivars. Genotypic variation among the progeny was investigated with random amplified polymorphic DNA (RAPD) analysis $(5,21,22)$. The main objective of this study was to determine if A. euteiches generates pathogenic and genotypic variation through production of zoospores.

\section{MATERIALS AND METHODS}

Aphanomyces cultures. Three parental strains, P134(1), AeMM187(1), and AOP46(1), derived from single zoospores, were chosen to represent pathogenic variability and different hosts and locations of origin (Table 1). Eighteen single-zoospore progeny were generated from each of these parental strains by inducing zoospore production as described by Mitchell and Yang (14). Zoospores were spread on an agar medium (17) and single germinating zoospore cysts were subcultured. The single-zoospore progeny are labeled P134(1-X), in which X is between 1 and 23; AeMM187(1-Y), in which $\mathrm{Y}$ is between 2 and 20; and AOP46(1-Z), in which $\mathrm{Z}$ is 


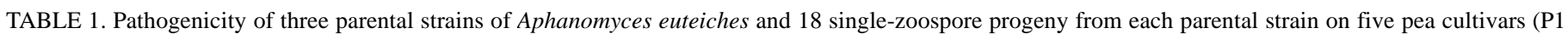
to P5), alfalfa (A), and bean (B)

\begin{tabular}{|c|c|c|c|c|c|c|c|c|c|c|}
\hline \multirow[b]{2}{*}{ Parent } & \multicolumn{2}{|c|}{ Origin of parent } & \multirow{2}{*}{$\begin{array}{l}\text { No. of single- } \\
\text { zoospore progeny }\end{array}$} & \multicolumn{7}{|c|}{ No. of zoospore progeny pathogenic on different hosts ${ }^{a}$} \\
\hline & Host & Location & & $\mathrm{P} 1$ & $\mathrm{P} 2$ & P3 & $\mathrm{P} 4$ & P5 & A & B \\
\hline P134(1) & Pea & Wisconsin & 18 & 17 & 16 & 15 & 17 & 17 & 0 & 0 \\
\hline AeMM187(1) & Pea & Minnesota & 18 & 0 & 0 & 0 & 18 & 18 & 15 & 15 \\
\hline AOP46(1) & Alfalfa & Wisconsin & 18 & 0 & 0 & 4 & 17 & 17 & 16 & 0 \\
\hline
\end{tabular}

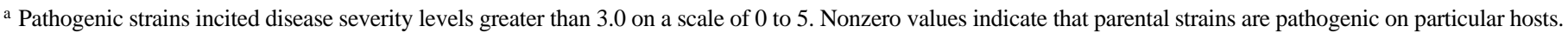

between 2 and 28. All strains were maintained on corn meal agar (Difco Laboratories, Detroit) at $4{ }^{\circ} \mathrm{C}$.

Pathogenicity testing. All parental and single-zoospore progeny strains of $A$. euteiches were tested for pathogenicity on five pea cultivars, snap bean, and alfalfa (Table 2 ). Two previously characterized strains, MF-1(1) and GB7(1), that infect alfalfa and bean, respectively, were included as pathogenicity controls $(7,12)$. Waxed, 160 -ml paper cups $(7.5 \times 6.5 \mathrm{~cm})$ containing vermiculite were sown with 3 seeds of bean or pea, or 8 to 10 seeds of alfalfa. Seeds of alfalfa were sown in combination with host-selective Rhizobium meliloti. Experiments were conducted in a greenhouse maintained at $24^{\circ} \mathrm{C} \pm 2{ }^{\circ} \mathrm{C}$ with a 12-h light/dark cycle. Seven days after sowing seed, 3,000 zoospores were injected with a pipetter $1 \mathrm{~cm}$ below the surface of vermiculite near seedlings in each cup. Cups were flooded at the time of inoculation and watered as needed to keep the vermiculite moist. Plants were harvested 14 days after inoculation, and disease severity (DS) and biomass loss were evaluated. DS (4) was determined visually using a 0 to 5 scale, in which $0=$ no macroscopic symptoms; $1=$ a few small, discolored spots on roots; $2=$ minor discoloration covering only part of the root system; $3=$ over $90 \%$ of the root system brown or yellowed, but no symptoms on the epicotyl/hypocotyl; $4=$ all of the root system brown or soft and the epicotyl/hypocotyl shriveled or brown; and 5 = plant dead. DS values $\leq 3.0$ were considered a nonpathogenic interaction. Below this DS level, there was minor or no root discoloration and no clear evidence of successful root infection, and attempts to isolate $A$. euteiches were unsuccessful. Ten pea and five alfalfa plants with characteristic symptoms of Aphanomyces root rot were examined microscopically for the presence of oospores. The experiment was organized as a split plot design with strain as the main plot factor and cultivar the subplot factor. Three replicate cups were used for noninoculated controls and for each combination of strain and plant host. The entire experiment was repeated once. Sets of whole pea and bean plants inoculated with the parental strains and nine progeny from each parental strain were dried for 8 days at $24^{\circ} \mathrm{C}$, and dry biomass was determined. Percent loss of biomass of inoculated versus noninoculated dry plants was calculated to measure the effect of disease on whole plant growth. DS and percent loss values among strains were evaluated with analysis of variance, and means were compared using Fisher's least significant difference test (SAS; SAS Institute, Inc., Cary, NC).

Polymerase chain reaction amplifications and RAPD assays. Aphanomyces strains were grown at $22^{\circ} \mathrm{C}$ with a 12 -h photoperiod in peptone-glucose broth (14) amended with $40 \mu \mathrm{g}$ of rifampicin per ml (Sigma Chemical Co., St. Louis) for 6 days. DNA was extracted (18), and DNA concentrations were measured with a fluorometer (model TKO 100; Hoefer Scientific Instruments, San Francisco, CA) and standardized for all strains prior to RAPD analyses. Four decanucleotide primers with arbitrary sequences obtained from the University of British Columbia, set 100/1, were used for RAPD analysis (Table 3). The primers were selected based on band clarity and numbers of total and polymorphic bands produced in previous studies with strains having different pathogenicity characteristics on pea, bean, and alfalfa (12). DNA from all parental and progeny strains of $A$. euteiches was amplified using each of the four primers. Each $25-\mu \mathrm{l}$ amplification reaction contained $15 \mathrm{ng}$ of primer,
TABLE 2. Code, characteristics, and source of pea (Pisum sativum), alfalfa (Medicago sativa), and bean (Phaseolus vulgaris) used for pathogenicity tests

\begin{tabular}{|c|c|c|c|c|}
\hline Code & $\begin{array}{l}\text { Host } \\
\text { spp. }\end{array}$ & Line/cv. & $\begin{array}{l}\text { Relative level of } \\
\text { resistance/tolerance }\end{array}$ & Source \\
\hline P1 & Pea & MN 313 & High & D. Davis, Univ. of MN (4) \\
\hline P2 & Pea & MN 314 & High & D. Davis, Univ. of MN (4) \\
\hline P3 & Pea & K902079 & Moderate & J. Kraft, USDA (10) \\
\hline P4 & Pea & WI8904 & Moderate & E. Gritton, Univ. of WI (8) \\
\hline P5 & Pea & Little Marvel & Low & $\begin{array}{l}\text { Burpee Seed Co., } \\
\text { Warminster, PA }\end{array}$ \\
\hline ALF & Alfalfa & Saranac & Low & Public variety \\
\hline BEAN & Bean & Early Gallatin & Low & $\begin{array}{l}\text { Rogers Bros. Seed Co., } \\
\text { Stanton, MN }\end{array}$ \\
\hline
\end{tabular}

${ }^{a}$ Resistance/tolerance to root rot caused by Aphanomyces euteiches.

$2 \mathrm{mM} \mathrm{MgCl} 2,2.5 \mathrm{ng}$ of genomic DNA, and 0.75 units of Taq DNA polymerase. Amplifications were conducted in a Tempcycler II (Coy Laboratory Products, Inc., Grass Lake, MI) programmed for one cycle of $94^{\circ} \mathrm{C}$ for $30 \mathrm{~s} ; 46$ cycles of $94^{\circ} \mathrm{C}$ for $40 \mathrm{~s}, 36^{\circ} \mathrm{C}$ for $1 \mathrm{~min}$, and $72^{\circ} \mathrm{C}$ for $2 \mathrm{~min}$; and one cycle of $72^{\circ} \mathrm{C}$ for $7 \mathrm{~min}$. Amplified samples $(11 \mu \mathrm{l})$ were loaded into composite gels made with $0.6 \%$ agarose (Fisher Scientific Co., Pittsburgh) and 0.44\% Synergel (Diversified Biotech, Boston) in 1× TAE buffer (40 mM Tris, $1.3 \mathrm{mM}$ EDTA, and $0.11 \%$ glacial acetic acid; $\mathrm{pH} 8.0$ ), and electrophoresis was conducted at $6.8 \mathrm{~V} / \mathrm{cm}$ for about $2.2 \mathrm{~h}$. RAPD banding patterns were analyzed as binary data representing the presence or absence of bands. Clear, intense bands were included in the analysis, while faint, inconsistent bands were excluded to improve reproducibility of results. Reproducibility of RAPD banding patterns was tested by amplifying DNA from strain P134(1) 14 times and by reamplifying DNA once and comparing resulting banding patterns from $55 \%$ (10 out of 18) of all single-zoospore progeny strains from each set. This replicated subset included all strains that contained polymorphic bands.

\section{RESULTS}

Pathogenicity comparisons. Noninoculated control plants remained healthy with DS $=0$. Strains MF-1(1) and GB7(1), used for positive pathogenicity controls on alfalfa and bean, incited DS levels of $3.3 \pm 1.1$ and $3.5 \pm 0.6$ on these hosts, respectively. Inoculated plants developed characteristic symptoms of Aphanomyces root rot, and all roots examined contained typical oospores. Two to four single-zoospore strains were identified in each group that incited significantly lower $(P=0.05)$ levels of DS than the parental strain (Table 4). No single-zoospore progeny strains were identified that incited significantly higher DS levels on any host than their parental strains (Figs. 1 to 3 ). Zoospore progeny that incited a significantly lower DS than the parental strain were detected on all plant hosts used except P3 (Table 4). The host range of some single-zoospore progeny was reduced compared with parental strains; however, none of the progeny had a host range greater than the corresponding parental strain on the seven host cultivars (Table 1). Some strains that may appear to be much different than the parental strain are not significantly different. These data also illustrate the different relative levels of resistance to Aphanomyces root rot among the five pea cultivars, with 


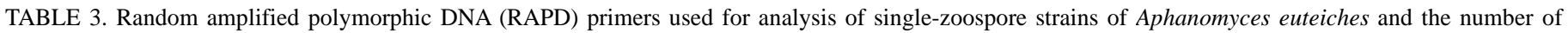
bands and RAPD genotypes detected in each group (A, B, and C) with each primer

\begin{tabular}{|c|c|c|c|c|c|c|c|c|c|c|c|}
\hline \multirow{2}{*}{$\begin{array}{l}\mathrm{UBC}^{\mathrm{a}} \\
\text { primer } \\
\text { code }\end{array}$} & \multirow{2}{*}{$\begin{array}{l}\text { Primer } \\
\text { sequence } \\
\left(5^{\prime} \text { to } 3^{\prime}\right)\end{array}$} & \multirow{2}{*}{$\begin{array}{l}\text { Mean number of bands } \\
\text { amplified per strain } \\
\text { (standard deviation) }\end{array}$} & \multicolumn{3}{|c|}{$\begin{array}{l}\text { Number of polymorphic bands within } \\
\text { groups of single-zoospore strains }\end{array}$} & \multicolumn{3}{|c|}{$\begin{array}{l}\text { Total number of bands among } \\
\text { all strains in groups }\end{array}$} & \multicolumn{3}{|c|}{$\begin{array}{c}\text { Number of RAPD genotypes } \\
\text { in groups }\end{array}$} \\
\hline & & & $\mathrm{A}^{\mathrm{b}}$ & $\mathrm{B}^{\mathrm{c}}$ & $\mathrm{C}^{\mathrm{d}}$ & $\mathrm{A}^{\mathrm{b}}$ & $\mathrm{B}^{\mathrm{c}}$ & $\mathrm{C}^{\mathrm{d}}$ & $\mathrm{A}^{\mathrm{b}}$ & $\mathrm{B}^{\mathrm{c}}$ & $\mathrm{C}^{\mathrm{d}}$ \\
\hline 2 & CCTGGGCTTG & $5.3(0.6)$ & 0 & 0 & 0 & 5 & 6 & 5 & 1 & 1 & 1 \\
\hline 12 & CCTGGGTCCA & $6.3(0.6)$ & 1 & 0 & 1 & 6 & 6 & 7 & 2 & 1 & 2 \\
\hline 31 & CCGGCCTTCC & $7.3(2.5)$ & 0 & 0 & 0 & 5 & 7 & 10 & 1 & 1 & 1 \\
\hline 33 & CCGGCTGGAA & $6.3(2.3)$ & 1 & 0 & 1 & 9 & 5 & 5 & 2 & 1 & 2 \\
\hline
\end{tabular}

a Code for primer sequence from the University of British Columbia.

b 18 single-zoospore strains in the P134(1-X) group.

c 18 single-zoospore strains in the AeMM187(1) group.

d 18 single-zoospore strains in the AOP46(1-X) group.

TABLE 4. Disease severity (DS) incited by parental strains and single-zoospore progeny (1-X) of Aphanomyces euteiches that incited significantly different $(P$ $=0.05)$ DS than the parental strain on one or more of five pea lines/cv. (P1 to P5), alfalfa (Alf), or snap bean (Bean) in two replicated experiments ${ }^{\mathrm{a}}$

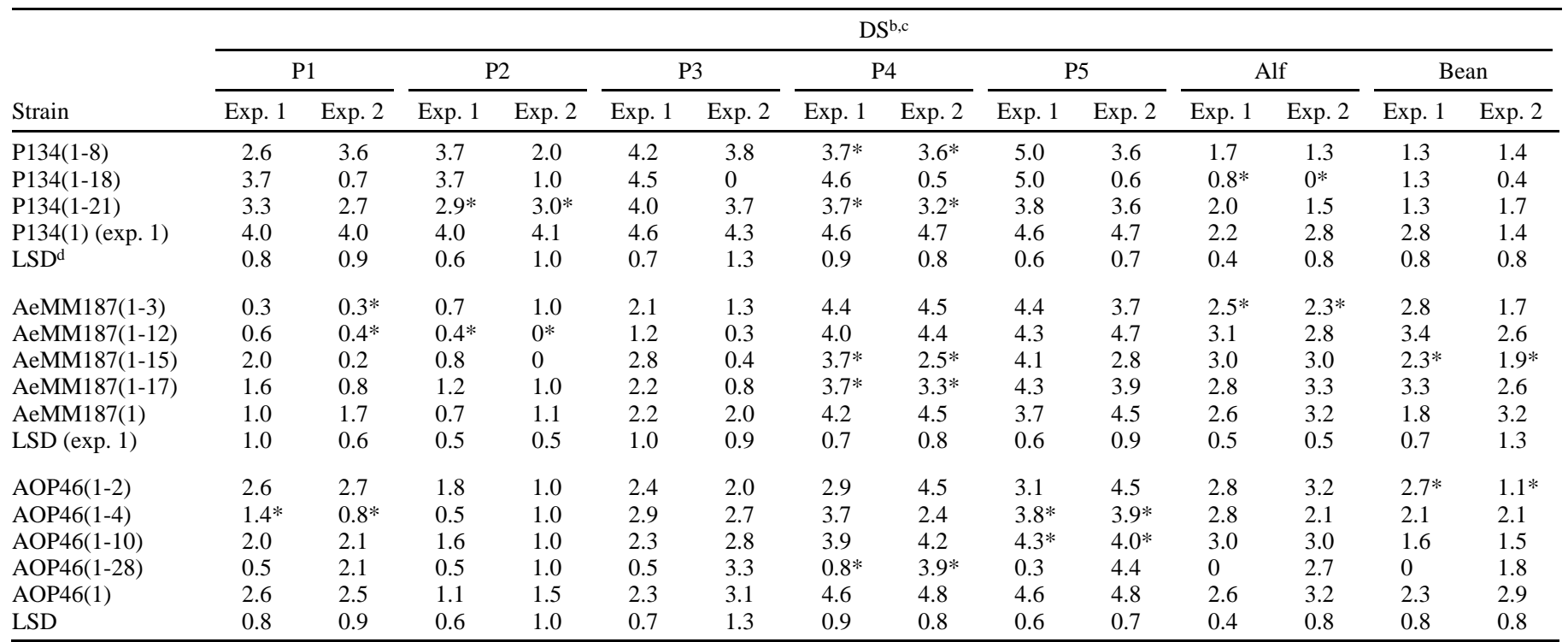

a 18 single-zoospore progeny from each of the three parental strains (P134(1), AeMM187(1), and AOP46(1)) were tested, and only those that incited significantly different DS on at least one host than the parental strain are shown.

${ }^{\mathrm{b}}$ DS is based on root infection using a 0 to 5 scale, in which 0 is healthy and 5 is dead. All DS data represent the mean from three replications.

c Values marked with an * represent strains that incited significantly different DS $(P=0.05)$ than the parental strain on a given plant host in each of two experiments.

${ }^{\mathrm{d}}$ Least significant difference.

$\mathrm{P} 2$ expressing the highest level of resistance, followed by P1, P3, $\mathrm{P} 4$, and P5.

Dry biomass of selected sets of inoculated and noninoculated plants were compared. Whole plant biomass was reduced in inoculated versus noninoculated plants for most treatments. Biomass loss values ranged from 0 to $45 \%$. However, most results were highly variable because of nonuniform growth habits of the plants (data not shown). Because of the variability, no significant differences $(P=0.05)$ in percent loss of biomass between parental and progeny strains was detected. Regression analysis revealed linear relationships between DS values and percent loss on all pea cultivars. For the groups of P134(1-X), AeMM187(1-Y), and AOP46(1-Z) zoospore progeny, the mean and standard deviation for the coefficients of determination $\left(r^{2}\right)$ values were $0.46(0.28)$, $0.81(0.12)$, and $0.64(0.22)$, respectively.

RAPD analysis. Genomic DNA from all parental and singlezoospore progeny strains was used in single-primer reactions to identify monomorphic and polymorphic amplified fragments ("markers"). Most markers were monomorphic in the groups of strains that consisted of a parental strain and 18 single-zoospore progeny (Table 3, Fig. 4). RAPD analysis with the four primers detected polymorphic markers within the P134(1-X) and AOP46(1-Z) groups of single-zoospore progeny. Polymorphic markers were not detected in the AeMM187(1-Y) group. There were 25, 24, and
27 RAPD markers detected in the P134(1-X), AeMM187(1-X), and AOP46(1-Z) groups of strains, respectively, and 8, 0 , and $7 \%$ of these markers were polymorphic. Primers 2 and 31 detected no polymorphisms and, hence, only one 'genotype', whereas, primers 12 and 33 detected polymorphisms and one or two 'genotypes' in each group of strains. Thus, primers 12 and 33 could potentially be used to distinguish particular strains. Primer 12 produced one marker band from strain P134(1-12) and another from strain AOP46(1-15), which distinguished these progeny from their parental and sibling strains. Primer 33 produced one marker from strain P134(1-7) and another from strain AOP46(1-27), which distinguished these progeny from their parental and sibling strains. Polymorphic markers were not detected in progeny that differed significantly from the parental strain in DS. Thus, no polymorphic markers were associated with the pathogenic variability detected on the seven plant cultivars. Replicated RAPD analysis of $55 \%$ of all strains, including all strains that exhibited polymorphisms, revealed the same bands in both replications and demonstrated that the RAPD banding patterns were reproducible.

\section{DISCUSSION}

A. euteiches is a variable species with regard to host range $(1,7,9$, $13,20)$. Its population biology is poorly understood, and the relative 


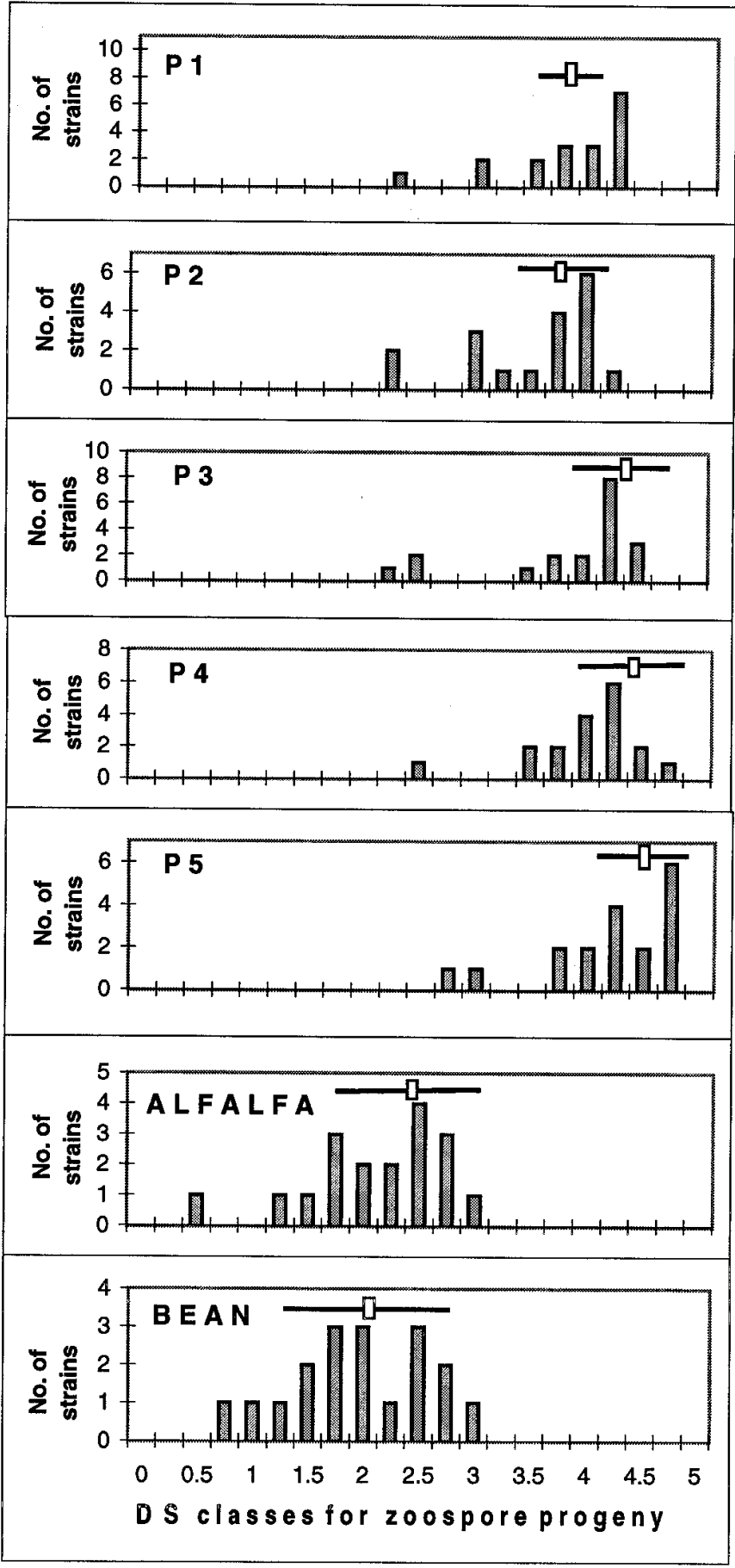

Fig. 1. Number of single-zoospore progeny strains from Aphanomyces euteiches parental strain P134(1) that incited different levels of disease severity (DS) on pea cultivars P1 to P5, alfalfa, and bean. The horizontal bar on each plot represents the mean and standard deviation of DS for P134(1). Data represent the mean from two experiments with three replications each. DS is based on severity of root infection using a 0 to 5 scale.

importance of asexual versus sexual reproduction for the generation of intraspecific variability is not known. Because of difficulties in germinating sexually produced oospores of A. euteiches, the occurrence and function of heterothallic crossing remains unknown. This is the first study to investigate variation and stability among single-zoospore strains from more than one parental strain of $A$. euteiches and to directly estimate genotypic variation. It demonstrates that asexual reproduction generates low levels of pathogenic and genotypic variability among zoospore progeny. Interpretations of these data must consider that a relatively

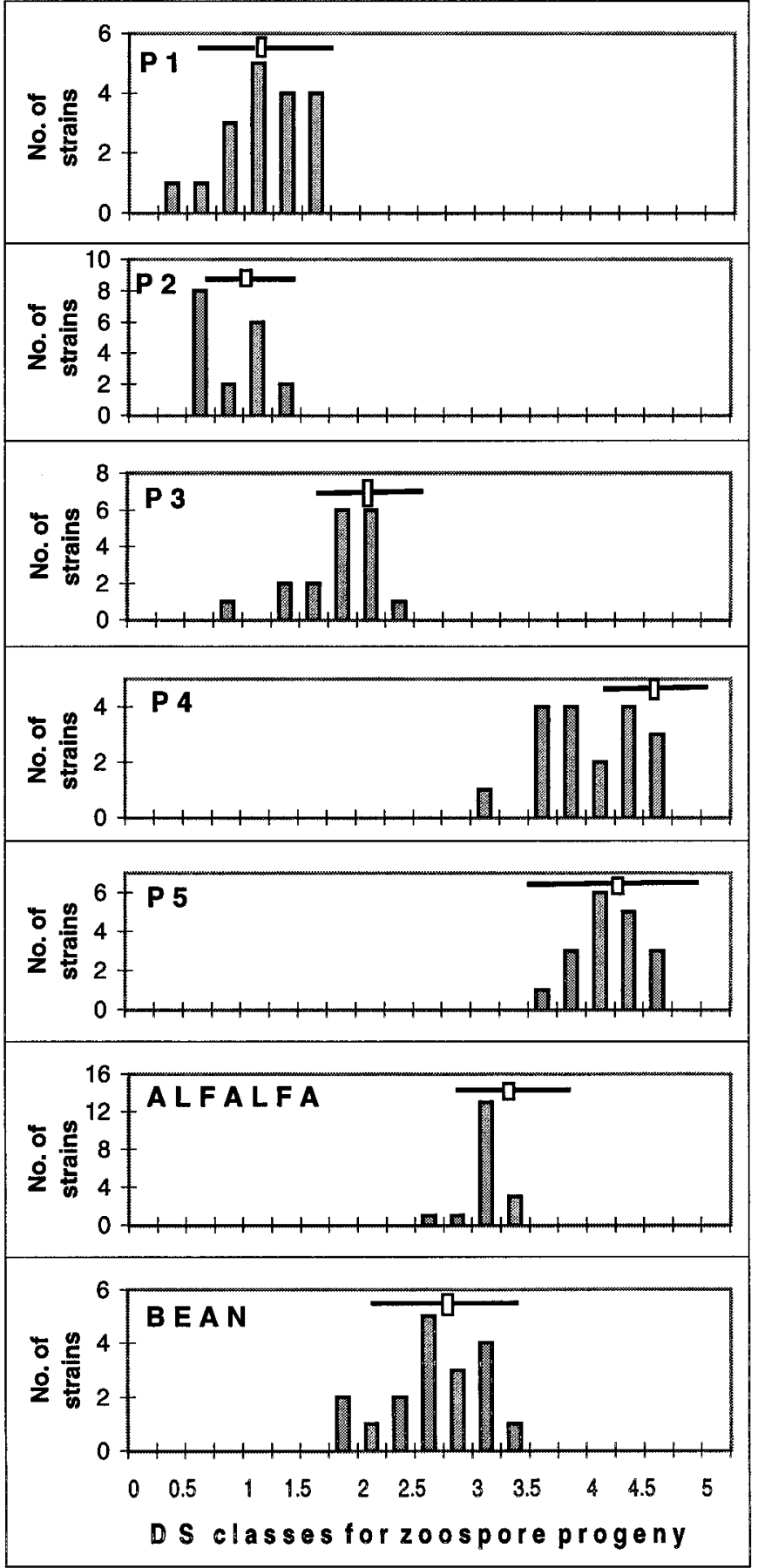

Fig. 2. Number of single-zoospore progeny strains from Aphanomyces euteiches parental strain AeMM187(1) that incited different levels of disease severity (DS) on pea cultivars P1 to P5, alfalfa, and bean. The horizontal bar on each plot represents the mean and standard deviation of DS for AeMM187(1). Data represent the mean from two experiments with three replications each. DS is based on severity of root infection using a 0 to 5 scale.

small number of single-zoospore strains were studied compared with the numbers that may be produced by single zoosporangia (e.g., up to 300) and, moreover, by single strains and populations (16). As discussed by Rutherford et al. (19), experimental logistics limit the number of strains that can be studied and compared. Regardless, the sample numbers were high enough in this study to detect genotypic and pathogenic variation among single-zoospore progeny.

A key hypothesis underlying this study was the following: asexual reproduction can produce progeny strains originating from 


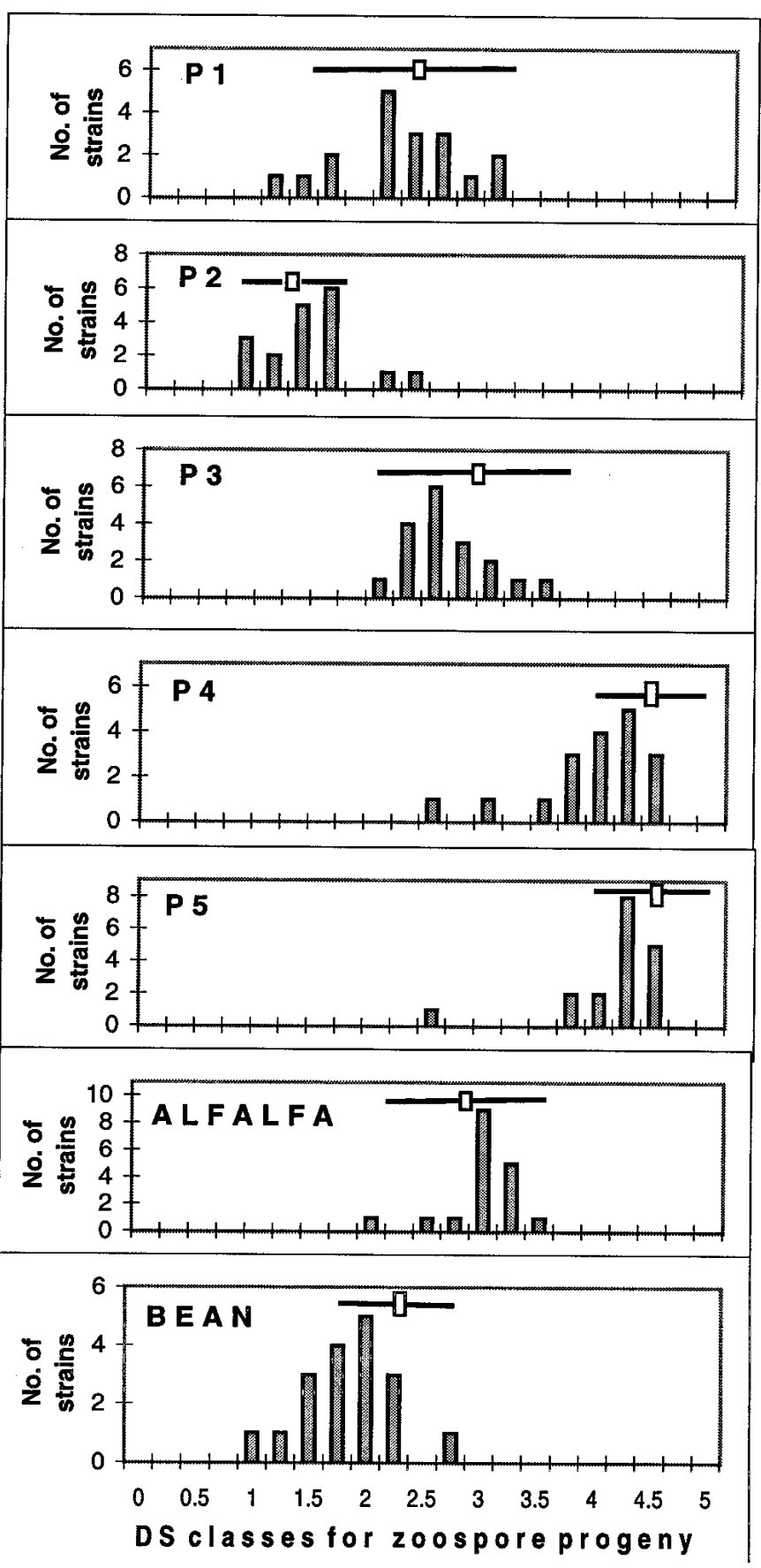

Fig. 3. Number of single-zoospore progeny strains from Aphanomyces euteiches parental strain AOP46(1) that incited different levels of disease severity (DS) on pea cultivars P1 to P5, alfalfa, and bean. The horizontal bar on each plot represents the mean and standard deviation of DS for AOP46(1). Data represent the mean from two experiments with three replications each. DS is based on severity of root infection using a 0 to 5 scale.

single zoospores that vary in pathogenicity traits from parental strain(s) and that have abilities to overcome new sources of host disease resistance. These new genotypes of A. euteiches may then undergo selection pressure by host species or cultivars with new sources of resistance, thus shifting the population structure towards the new pathogen genotypes. Although DS varied between some parental and single-zoospore progeny strains on individual host species, all the significant pathogenicity changes detected in this study were in the direction of decreased DS on given plant cultivars as compared with the parental strain. No progeny incited significantly $(P=0.05)$ greater DS than the corresponding parental strain on any host. Several progeny in all three single-zoospore groups incited significantly lower DS than the parental strain on at least three of the seven plant hosts, and some progeny lost pathogenicity on particular hosts. In addition, the trend was for many progeny strains to incite lower, although insignificant, levels of DS than the mean DS incited by the parental strain. In no case was the host range expanded for progeny beyond that of the parental strains, but in some cases it was reduced.

Caten (2) reported zoospore variability in $P$. infestans, but suggested it is not an important source of new fungal genotypes that overcome novel sources of resistance. This study and a previous study (9) with A. euteiches suggest that the same may be true for A. euteiches. This study contrasts with a study by Holub et al. (9) that used one cultivar each of pea, alfalfa, and bean, and did not directly study genotypic traits. They (9) studied pathogenic variation among single-zoospore progeny from one wide-hostrange parental mass isolate. They also reported that many single-zoospore progeny were less pathogenic than the parent culture. In both this and Holub et al. (9) studies, the trend towards lower pathogenicity of progeny compared with parental strains was more pronounced on pea than on alfalfa or bean cultivars.

Another goal of this study was to determine if pathogenic variation was based on genomic mutations or rearrangements rather than variable gene expression or adaptive physiological traits. RAPD analysis has been used successfully for similar studies (5) and was used to detect variable genetic markers in this study. The RAPD analysis revealed genetic variability within two of the three groups of single-zoospore progeny. The polymorphic RAPD markers detected, however, were not found to be associated with the strains that exhibited pathogenic variation. The results suggest that genetic variation is generated through asexual reproduction, but it has not been confirmed that the pathogenic variation is due to genotypic change. Testing of additional single-zoospore progeny and using additional primers would increase the chance of detecting putative genetic loci that are related to pathogenic variability.

The detection of variable RAPD markers with a relatively small number of primers and single-zoospore progeny suggests that genetic change may occur in A. euteiches during asexual reproduction. It is unknown if any of the variable genetic markers detected are associated with pathogenicity or any functional genes. The pathogenic variability detected, however, suggests that changes occurred in genes or gene expression related to pathogenicity. Considering that pathogenicity is often a polygenic trait and the spontaneous mutation frequency per gene in fungi is estimated at $1 \times 10^{-6}(6)$, it seems likely that the variation detected in single-zoospore progeny is due to a mechanism other than spontaneous mutation. The genetics of inheritance in A. euteiches are poorly understood, and no genetic studies with this pathogen have been done to provide information to explain the results. Studies of $P$. infestans may provide some clues to understanding the biology of $A$. euteiches. Caten (3) suggests that individual mycelia of $P$. infestans are composed of a mixture of different cytoplasmic genotypes that are normally available for selection. Leach and Rich (11) suggest that heterokaryosis and parasexuality may play a role in generating variability among single zoospores of $P$. infestans.

A. euteiches is a variable organism and may have the capacity to adapt to selection pressures through asexual reproduction. Variability among single-zoospore cultures must be considered when conducting any laboratory, field, or disease-resistance study with this pathogen. In particular, care must be taken when choosing single-zoospore cultures for specific investigations. Additional studies are needed to elucidate the genetics and variability in this organism if we hope to understand its population biology and structure and ultimately to develop successful methods to control Aphanomyces root rot diseases. 

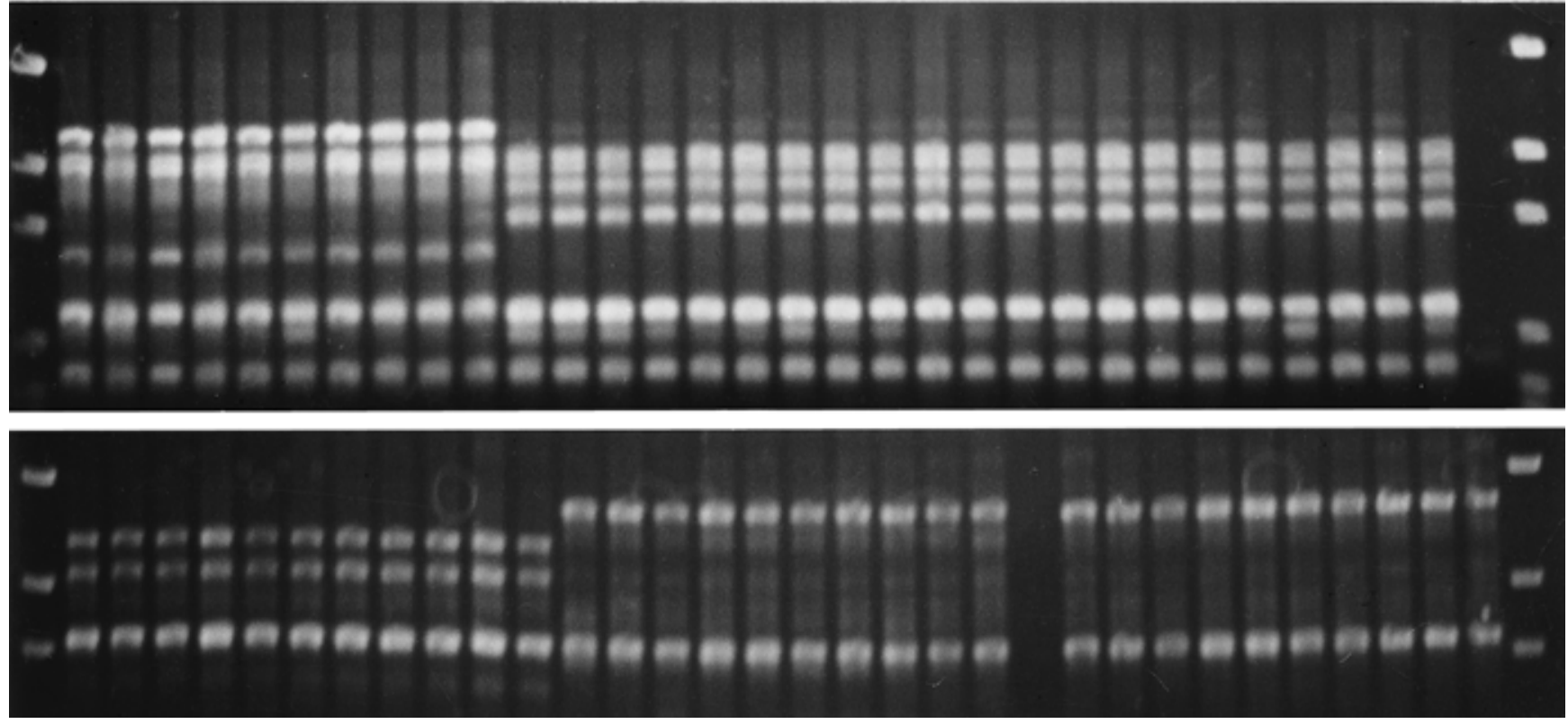

Fig. 4. Random amplified polymorphic DNA banding patterns generated with primers 2 (top panel) and 12 (bottom panel) using total genomic DNA from subsets of strains from three groups of single-zoospore strains. The first and last lanes in the top and bottom panels are DNA size markers with the top five visible bands having sizes of 2.6-, 1.6-, 1.2-, 0.7-, and 0.5-kb pairs. (Top) Lanes 2 to 10 are single-zoospore progeny strains P134(1-X), in which X is 1, 2, 5, 7, 10, 12, 13, 17, and 22. Lane 11 is parental strain P134(1). Lane 12 is P134(1-23). Lanes 13 to 21 are single-zoospore progeny strains AeMM187(1-Y), in which Y is 2, $3,5,6,9,12,13,14$, and 19, and lane 22 is parental strain AeMM187(1). Lanes 24 to 32 are single-zoospore progeny strains AOP46(1-Z), in which Z is 2, 3, 7, 10, 13, 14, and 27. Lane 33 is parental strain AOP46(1). Polymorphic bands appear in lanes 7 and 29 slightly above the 0.7-kbp marker. (Bottom) Lanes 2 to 11 contain the same strains as appear in lanes 2 to 11 in the top panel. Lanes 12 to 21 contain the same strains as appear in lanes 13 to 22 of the top panel. Lanes 22 to 31 contain the same strains that appear in lanes 24 to 33 of the top panel, except lane 29 contains AOP46(1-15). Lane 32 is strain AOP46(1-15), and lane 33 is a water (no DNA added) control.

\section{ACKNOWLEDGMENTS}

Published as contribution 191220019 of the series of the Minnesota Agricultural Experiment Station on research conducted under Project 2293, and supported by general agricultural research funds. We thank C. Grau for providing the isolates of A. euteiches and for helpful input.

\section{LITERATURE CITED}

1. Beute, M. K., and Lockwood, J. L. 1967. Pathogenic variability in Aphanomyces euteiches. Phytopathology 57:57-60.

2. Caten, C. E. 1970. Spontaneous variability of single isolates of Phytophthora infestans. II. Pathogenic variation. Can. J. Bot. 48:897-905.

3. Caten, C. E. 1971. Single zoospore variation in Phytophthora infestans and attenuation of strains in culture. Trans. Br. Mycol. Soc. 56:1-7.

4. Davis, D. W., Fritz, V. A., Pfleger, F. L., Percich, J. A., and Malvick, D. K. 1995. MN 144, MN 313, and MN 314: Garden pea lines resistant to root rot caused by Aphanomyces euteiches Drechs. Hortic. Sci. 30:639-640.

5. Doudrick, R. L., Nance, W. L., Nelson, C. D., Snow, G. A., and Hamelin, R. C. 1993. Detection of DNA polymorphisms in a single urediniosporederived culture of Cronartium quercuum f. sp. fusiforme. Phytopathology 83:388-392.

6. Fincham, J. R. S., Day, P. R., and Radford, A. 1979. Fungal Genetics. 4th ed. University of California Press, Berkeley.

7. Grau, C. R., Muehlchen, A. M., Tofte, J. E., and Smith, R. R. 1991. Variability in virulence of Aphanomyces euteiches. Plant Dis. 75:1153-1156.

8. Gritton, E. T. 1990. Registration of five root rot resistant germplasm lines of processing pea. Crop Sci. 30:1166-1167.

9. Holub, E. B., Grau, C. R., and Parke, J. L. 1991. Evaluation of the forma specialis concept in Aphanomyces euteiches. Mycol. Res. 95:147-157.

10. Kraft, J. M. 1992. Registration of 90-2079, 90-2131, and 90-2322 pea germplasms. Crop Sci. 32:1076.

11. Leach, S. S., and Rich, A. E. 1969. The possible role of parasexuality and cytoplasmic variation in race differentiation in Phytophthora infestans. Phytopathology 59:1360-1365.

12. Malvick, D. K., Grau, C. R., and Percich, J. A. Characterization of Aphanomyces euteiches strains based on pathogenicity tests and random amplified polymorphic DNA analysis. Mycol. Res. In press.

13. Manning, M. A., and Menzies, S. A. 1984. Pathogenic variability in isolates of Aphanomyces euteiches from New Zealand soils. N.Z. J. Agric. Res. 27:569-574.

14. Mitchell, J. E., and Yang, C. Y. 1966. Factors affecting growth and development of Aphanomyces euteiches. Phytopathology 56:917-922.

15. Moore-Landecker, E. 1996. Fundamentals of the Fungi. Prentice Hall, Upper Saddle River, NJ.

16. Papavizas, G. C., and Ayers, W. A. 1974. Aphanomyces species and their root diseases in pea and sugarbeet. U.S. Dep. Agric. Agric. Res. Serv. Tech. Bull. 1485.

17. Pfender, W. F., Delwiche, P. A., Grau, C. R., and Hagedorn, D. J. 1984. A medium to enhance recovery of Aphanomyces from infected plant tissue. Plant Dis. 68:845-847.

18. Raeder, U., and Broda, P. 1985. Rapid preparation of DNA from filamentous fungi. Lett. Appl. Microbiol. 1:17-20.

19. Rutherford, F. S., Ward, E. W. B., and Buzzell, R. I. 1985. Variation in virulence in successive single-zoospore propagations of Phytophthora megasperma f. sp. glycinea. Phytopathology 75:371-374.

20. Sundheim, L. 1972. Physiologic specialization in Aphanomyces euteiches. Physiol. Plant Pathol. 2:301-306.

21. Welsh, J., and McClelland, M. 1990. Fingerprinting genomes using PCR with arbitrary primers. Nucleic Acids Res. 18:7213-7218.

22. Williams, J. G. K., Kubelik, A. R., Livak, K. J., Rafalski, J. A., and Tingey, S. V. 1990. DNA polymorphisms amplified by arbitrary primers are useful as genetic markers. Nucleic Acids Res. 18:6531-6535. 


\section{Erratum}

\section{Vol. 88, No. 1, January 1998}

In the manuscript entitled "Variation in Pathogenicity and Genotype Among Single-Zoospore Strains of Aphanomyces euteiches" by D. K. Malvick and J. A. Percich (Phytopathology 88:52-57), Figure 4 and caption are as follows
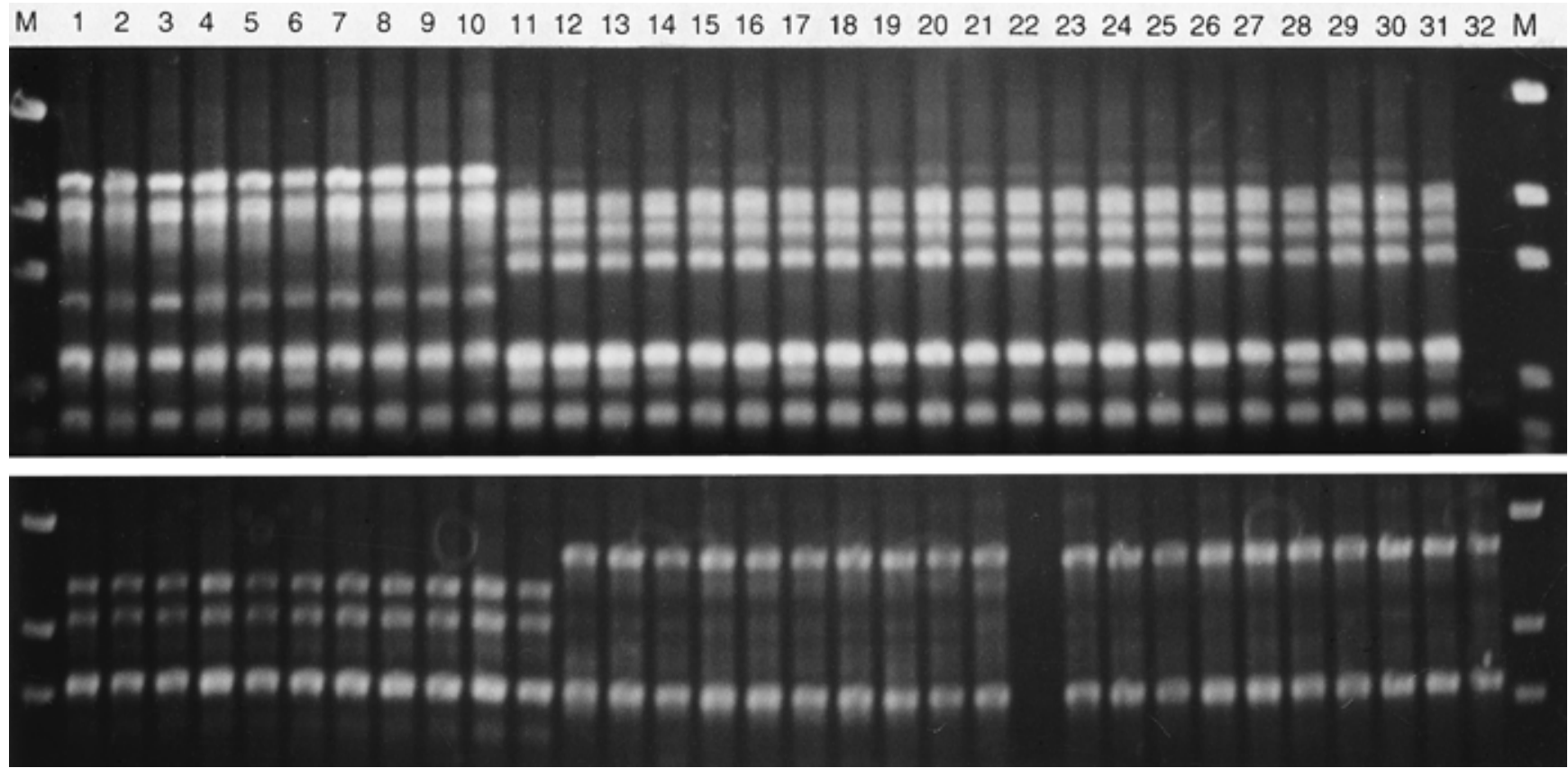

Fig. 4. Random amplified polymorphic DNA banding patterns generated with primers 12 (top panel) and 2 (bottom panel) using total genomic DNA from subsets of strains from three groups of single-zoospore strains of Aphanomyces euteiches. The first and last lanes are DNA size markers (M) with the top five visible bands having sizes of 2.6-, 1.6-, 1.2-, 0.7-, and 0.5-kb pairs. (Top) Lanes 1 to 10 are single-zoospore progeny strains P134(1-X), in which X is 1, 2, 5, 7, $10,12,13,17,22$, and 23. Lanes 11 to 19 are single-zoospore progeny strains AeMM187(1-Y), in which $\mathrm{Y}$ is $2,3,5,6,9,12,13,14$, and 19 . Lane 20 is parental strain AeMM187(1). Lanes 21 to 30 are AOP46(1-Z), in which Z is 2, 3, 5, 7, 12, 13, 14, 15, 18, and 27. Lane 31 is parental strain AOP46(1), and lane 32 is a water (no DNA added) control. Polymorphic bands appear in lanes 6 and 28 slightly above the 0.7 - kbp marker. (Bottom) Lanes 1 to 10 contain the same strains that appear in lanes 1 to 10 of the top panel. Lane 11 is P134(1-23). Lanes 12 to 20 contain the same strains that appear in lanes 11 to 19 of the top panel. Lanes 21 and 23 to 30 contain the same strains that appear in lanes 21 to 30 of the top panel. DNA was not amplified in lane 22. Lane 31 is strain AOP46(1-28). Lane 32 is parental strain AOP46(1). 